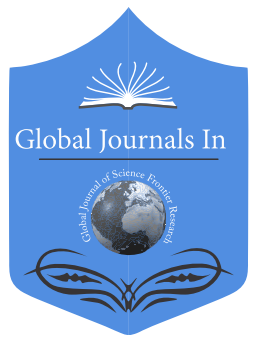

\title{
Quantification of Noise and Air Quality Risks at a Crude Oil Flow Station
}

\author{
By Kennedy A. Osakwe
}

RMIT University

Abstract-Background: Occupational and environmental hazards are continually encountered by oil and gas workers in operational facilities. This study thus aimed at quantifying the noise level and air quality parameters within a crude oil flow station in the Niger Delta Region of Nigeria. Methods: The study was conducted in one of the crude oil facilities at Escravosin Delta State of Nigeria. A descriptive, crosssectional design was adopted in the study. Area noise measurements were undertaken at 40 locations within and outside the facility using a CEL-485 (serial number 109776). Air quality measurements were undertaken in fourteen (14) locations within the facility using CASELLA Micro dust pro (Dust Monitor) and Multi-Gas Meter.

Keywords: air quality, occupational hazards, exposure, noise, noise assessment.

GJSFR-H Classification: FOR Code: 040699

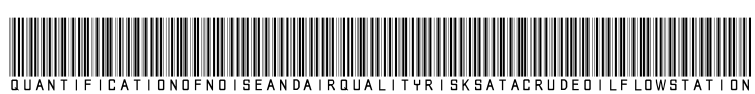

Strictly as per the compliance and regulations of:

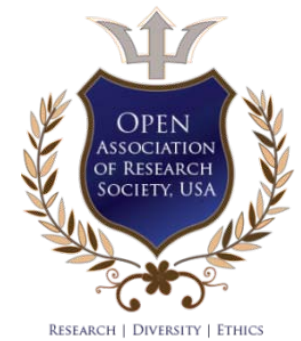

(C) 2020. Kennedy A. Osakwe. This is a research/review paper, distributed under the terms of the Creative Commons AttributionNoncommercial 3.0 Unported License http://creativecommons.org/licenses/by-nc/3.0/), permitting all non commercial use, distribution, and reproduction in any medium, provided the original work is properly cited. 


\title{
Quantification of Noise and Air Quality Risks at a Crude Oil Flow Station
}

\author{
Kennedy A. Osakwe
}

\begin{abstract}
Background: Occupational and environmental hazards are continually encountered by oil and gas workers in operational facilities. This study thus aimed at quantifying the noise level and air quality parameters within a crude oil flow station in the Niger Delta Region of Nigeria. Methods: The study was conducted in one of the crude oil facilities at Escravosin Delta State of Nigeria. A descriptive, crosssectional design was adopted in the study. Area noise measurements were undertaken at 40 locations within and outside the facility using a CEL-485 (serial number 109776). Air quality measurements were undertaken in fourteen (14) locations within the facility using CASELLA Micro dust pro (Dust Monitor) and Multi-Gas Meter. Measured air quality parameters included Oxides of Sulphur (SOx) (ppm), Oxides of Nitrogen (NOx) (ppm), Carbon Monoxide (CO) (ppm), Carbon dioxide $\left(\mathrm{CO}_{2}\right)$ (ppm), Particulate matter (SPM) $\left(\mu \mathrm{g} / \mathrm{m}^{3}\right)$ and Volatile Organic Compounds (VOC) (ppm). Results: While the noise level measured within the facilityranged from 76.8$111.7 \mathrm{~dB}(\mathrm{~A})$, measured locations outside the facility ranged from 32.6-69.5 dB (A). Air quality parameters within the facility were found to exceed the limits established by the Directorate of Petroleum Resources in Nigeria. Conclusion. Operation of a functional crude oil flow station simultaneously contributes to noise and air pollution, which are potentially harmful to exposed workers within the facility. The results of this study generated new issues concerning health and safety practices in the oil and gas industry, which could lead to future research. Innovative ways to mitigate the harmful impact of exposure to noise and air pollutants should be deployed concurrently with the operation of a crude oil facility.
\end{abstract}

Keywords: air quality, occupational hazards, exposure, noise, noise assessment.

\section{InTRODUCTION}

T he oil and gas industry has grown to become an economic contributor to Nigeria's economy, which is also a large employer of the labor force in Nigeria[1]. However, there have been concerns over the potential health and environmental impacts of crude oil production in Nigeria[2]. Though resources from the oil and gas industry sustain the Nigerian economy, activities in the oil industry pose potential risks especially to the frontline workers who might be exposed daily[3]. Occupational hazards refer to workplace factors, processes, circumstances, material substances; that have the potential to cause harm and

Author: RMIT University, 124 La Trobe St, Melbourne VIC 3000, Australia, Senior Lecturer \& Programme Manager, Occupational Health \& Safety programme, School of Property, Construction and Project Management (PCPM), RMIT University, Melbourne, Australia, BDS, MPH, CMFOH, PhD, FRSP. e-mail: kennedy.osakwe@rmit.edu.au thus pose a threat to the health and safety of workers in all occupations [4]. It presents in the form of occupational health and safety hazards. Additionally, environmental hazards could mean any situation or state of events that poses a threat to the surrounding natural environment and adversely affects the health of an individual [5].

It is, however, important to distinguish exposures within the oil and gas facilities from exposures outside these facilities, which lies in the confines of the environment. Globally, a lot of attention has been devoted to the environmental impact of oil and gas activities, with little attention shown on the impact on frontline workers in the occupational domain. Occupational and Environmental hazards could broadly be classified as physical, ergonomic, chemical, biological, mechanical, and psychosocial hazards [6]. Ergonomic hazards in the oil and gas industry include manual handling, lifting, lowering, pulling, pushing, confined workspace access, narrow walkways, prolonged awkward posture and poor body mechanics [7]. Physical hazards in the oil and gas industry include ionizing and non-ionizing radiation, noise, whole-body vibration and vibrating hand-tools, inclement weather [7]. Chemical hazards include carcinogens like benzene, various acids, hydrogen sulfide, crude, mud component of drilling fluid, welding or cutting fumes as well as irritant, toxic, corrosive and sensitizing substances[8]. Biological hazards could be legionella, food-borne pathogens, to name but a few[7]. While these lists are in exhaustive, they constitute potentially harmful risks to frontline oil and gas workers. Exposure scenarios and categories of causative activities in the oil and gas industry that generates most of these hazards include seismic operations, exploration and drilling, production, preventive and corrective maintenance, processing of hydrocarbon, transportation of the unfinished and finished product, de-commissioning of installation etc[9]. During these activities, employees could further be exposed to varieties of hydrocarbon waste, process materials and substances in the work environment that portend significant occupational risk[9].

Relatedly, workers are exposed to unintentional gas leaks from oil and gas activities arising from equipment leaks, process venting, evaporation losses, disposal of waste gas streams (e.g., by venting or flaring), accidents and equipment failures, methane 
emissions from wastewater handling, methane from industrial wastewater and sludge streams, and nitrous oxide from human sewage. These hazards pose a variety of significant health and safety risks[10]. Crude oil and natural gas composition vary slightly, according to reservoirs; however, it possesses consistent toxicological properties. Chemicals such as polycyclic aromatic hydrocarbons (PAHs) and benzene are toxic components of crude oil and are a source of concern[8]. These chemicals along with others found in crude oil are volatile and capable of moving from the oil into the air. Once airborne, they can blow over the sea and creeks for kilometers, reaching communities far from the source of emission. Though they may be perceived as hydrocarbon odors; workers and people living in neighboring communities will be exposed to crude oil and natural gas aerosols in the air[8]. Differences in exposure will occur based on location, work and personal activities, age, diet, use of protective equipment, and other factors. Exposure to a combination of toxic chemicals, especially if they are capable of causing harm to organs in the body, increases the potential for adverse health effects $[8,10]$.

Gas flares releases a significant amount of greenhouse gases and causes the release of particulate matter, sulfur dioxide, nitrogen dioxide, and carcinogenic substances such as benzo(a)pyrene, dioxin, benzene and toluene, which can have severe health effects on unprotected frontline workers [1].The paucity of information on the impact of hazards associated with oil and gas activities on frontline workers spurred the interest for this study. This study thus set out to examine and quantify the noise levels and amount of air pollution within crude oil flow stations in the Niger Delta region of Nigeria as representative hazards. The findings could be used as a guide to improve health and safety practices as well as drive further research within the stated research scope.

\section{il. Methodology}

The study was carried out in a crude oil flow station, an installation located along the Escravos River in the Delta State of Nigeria. Though the facility is about 200 meters from the Escravos village, it is also surrounded by numerous fishing settlements and villages. Geographically, the installation lies between latitudes $4^{\circ}$ and $6^{\circ}$ north of the equator and longitudes $5^{\circ}$ and $9^{\circ}$ East of the Greenwich Meridian [11]. The installation is bounded on the North by the Escravosriver, on the South by Escravos village, on the East by a mangrove swamp and numerous fishing settlements located about 80 meters away and on the West by the Nigeria Atlantic Ocean continental shelf. Accessibility to the site is by sea and air. The facility was chosen for the study because of the dense activities of oil exploration and production with the potentials for hazard generation in and around the installation. The flow station receives crude oil from surrounding wellheads through numerous flow lines and rises to the separators; which separate the crude, gas and water before pumping out through an export pipeline to a distant gathering facility.

The materials used in this study includesCasella Micro dust pro (Dust Monitor), and Multi-Gas Meter for air quality analysis, CEL-485 (serial number 109776) Sound Level Meter and CEL-282 calibrator for noise survey.

To assess the risk of gas flare and fugitive emissions within the facility, air quality measurement was conducted. Air sampling with measurement of suspended particulate matter and air quality profiling was done using Casella Micro dust pro (Dust Monitor) and Multi-Gas Meter respectively, with readings taken from 14 sites in the facility environment. The Multi-Gas Meter was used to assess for Sulfur Oxides (SOx), Nitrogen Oxides (NOx), Carbon Monoxide (CO), Carbon dioxide $\left(\mathrm{CO}_{2}\right)$, and Volatile organic compounds. The dust monitor uses the principle of near forward light scattering to measure dust particle concentration. The air quality meter uses the principle of extractive sampling and ultraviolet fluorescence [12].

Area noise measurements were undertaken in 40 locations within and outside the facility using a CEL485 (serial number 109776), which was calibrated using a CEL-282 calibrator (serial number 3/10921327). Noise measurements as 30 seconds LAeqs(averages) and frequency band analysis were undertaken at 20 locations approximately 5 meters apart on a grid within the facility running at $75-80 \%$ of its capacity on the day of noise survey; and 20 locations outside the facility (in the administrative and accommodation buildings). Purposive sampling technique was adopted in the selection of the 40-measurement locations within the facility. After putting on the hearing protection devices (Ear-muffs and Ear-plugs), the sound level meter (SLM), was switched on and turned to the high measurement mode. The measurement trigger was activated with the meter microphone pointed at the point of interest and noise level was measured and recorded. The sound level meter was calibrated at Casella measurement laboratories, the UK using a standard acoustic calibrator (94dB, $110 \mathrm{~Hz}$ sine wave). A-weighting for the general noise sound level was chosen. The instrument was held in the hand of the author and the microphone pointed at suspected noise sources. The MAX and MIN (maximum, minimum) modes were selected and the sound pressure level was displayed at their maximum and minimum readings. The average reading was then taken for each of the forty locations within and outside the facilities. Data was inputed with the Microsoft Excel spreadsheet (2007 version) and then imported into the Statistical Package for Scientific Solutions (SPSS) version 21.0 (statistical software package) for analyses. Tables and 
graphs were used for data presentation and means were used for data expresssion.

\section{ili. Results}

In this study, assessment of the noise levels within and outside the Escravos flow station gave the following results. All twenty locations measured within the facility had high noise levels ranging from 76.8 $111.7 \mathrm{~dB}(\mathrm{~A})$. Also, all twenty measured locations outside the facility revealed low noise levels ranging from 32.6$69.5 \mathrm{~dB}(\mathrm{~A})$. These details are shown in Tables 1 and 2 below.

Table 1: Noise measurement within the facility

\begin{tabular}{cccc}
\hline SN & Locations & $\begin{array}{c}\text { LAeq dB } \\
(\mathrm{A})\end{array}$ & $\begin{array}{c}\text { Lmax dB } \\
(\mathrm{A})\end{array}$ \\
\hline 1 & Pump 1(Operational) & 89.5 & 90.9 \\
2 & Pump 2(Operational) & 90.0 & 94.1 \\
3 & Pump 3(Operational) & 90.6 & 90.7 \\
4 & Pump 4 Station & 85.1 & 87.1 \\
5 & Pump 5 Station & 85.0 & 86.5 \\
6 & Turbine Unit & 86.0 & 87.4 \\
7 & Caterpillar Generator & 111.7 & 112.3 \\
8 & Air compressor & 88.3 & 89.2 \\
9 & Surge Vessel 2 & 85.2 & 86.4 \\
10 & Saver pit & 78.6 & 83.5 \\
11 & Low Pressure Separator 1 & 83.8 & 88.3 \\
12 & High Pressure Separator 1 & 84.1 & 87.0 \\
13 & Test Separator 1 & 80.2 & 81.8 \\
14 & Surge Vessel 1 & 82.8 & 84.9 \\
15 & Metering skid & 82.6 & 84.2 \\
16 & Manifold area & 82.2 & 83.0 \\
17 & Low Pressure Separator 2 & 83.4 & 84.0 \\
18 & High Pressure Separator 2 & 80.8 & 81.6 \\
19 & Test Separator 2 & 81.4 & 82.1 \\
20 & Mustering Area & 76.8 & 80.8 \\
& & & \\
\hline
\end{tabular}

Table 2: Noise measurements outside the facility

\begin{tabular}{cccc}
\hline SN & Locations & LAeq dB (A) & Lmax dB(A) \\
\hline 1 & Kitchen & 69.5 & 70.9 \\
2 & Laundry & 66.0 & 74.1 \\
3 & Accommodation Room & 46.6 & 50.7 \\
4 & Recreation & 45.1 & 55.1 \\
5 & Reception & 45.0 & 56.5 \\
6 & Team leaders Office & 41.0 & 53.4 \\
7 & Operations Office & 42.7 & 44.3 \\
8 & Mechanical Office & 41.3 & 49.2 \\
9 & Beach Masters Office & 42.2 & 44.4 \\
10 & Clinic & 38.6 & 43.5 \\
11 & Boat Men Office & 39.8 & 44.3 \\
12 & Maintenance Office & 34.1 & 37.0 \\
13 & Camp Boss Office & 44.2 & 45.8 \\
14 & Electrical Office & 42.8 & 44.9 \\
15 & Instrument Office & 32.6 & 34.2 \\
16 & Workshop & 42.2 & 43.0 \\
17 & Station Attendant Office & 53.4 & 54.0 \\
18 & Tool Pushers office & 45.8 & 51.6 \\
19 & Location Planner Office & 51.4 & 52.1 \\
20 & Sewage treatment Room & 46.8 & 50.8 \\
\hline
\end{tabular}


Air quality analysis showed that respective parameters (Particulate Matter, Oxides of Sulphur, Oxides of Nitrogen, Carbon Monoxide, Carbon Dioxide, and Volatile Organic compound) exceeded the normal limits provided by the Directorate of Petroleum Resources of Nigeria. This is shown in Table 3. Particulate matter (SPM) gave the highest observed levels. This is shown in Figure 1.

Table 4: Air quality analysis around the facility

\begin{tabular}{lccccc}
\hline \multicolumn{1}{c}{ Parameters } & $\begin{array}{c}\text { DPR } \\
\text { Limit }\end{array}$ & Sample 1 & Sample 2 & Sample 3 & $\begin{array}{c}\text { Average } \\
\text { values }\end{array}$ \\
\hline Oxides of Sulfur $(\mathrm{SOx})(\mathrm{ppm})$ & 0.05 & 0.06 & 0.05 & 0.06 & 0.14 \\
Oxides of Nitrogen $(\mathrm{NOx})(\mathrm{ppm})$ & 0.07 & 0.08 & 0.08 & 0.09 & 0.25 \\
Carbon Monoxide $(\mathrm{CO})(\mathrm{ppm})$ & 8 & 8 & 9 & 10 & 9 \\
Carbon dioxide $\left(\mathrm{CO}_{2}\right)(\mathrm{ppm})$ & $\mathrm{N} / \mathrm{A}$ & 28.7 & 30.1 & 30.5 & 29.8 \\
$\begin{array}{l}\text { Particulate matter }(\mathrm{SPM})\left(\mu \mathrm{g} / \mathrm{m}^{3}\right) \\
\text { Volatile Organic Compounds }\end{array}$ & $60-90$ & 200.0 & 300.0 & 360.0 & 287 \\
(VOC) (ppm) & N/A & 30 & 30 & 30 & 30 \\
\hline
\end{tabular}

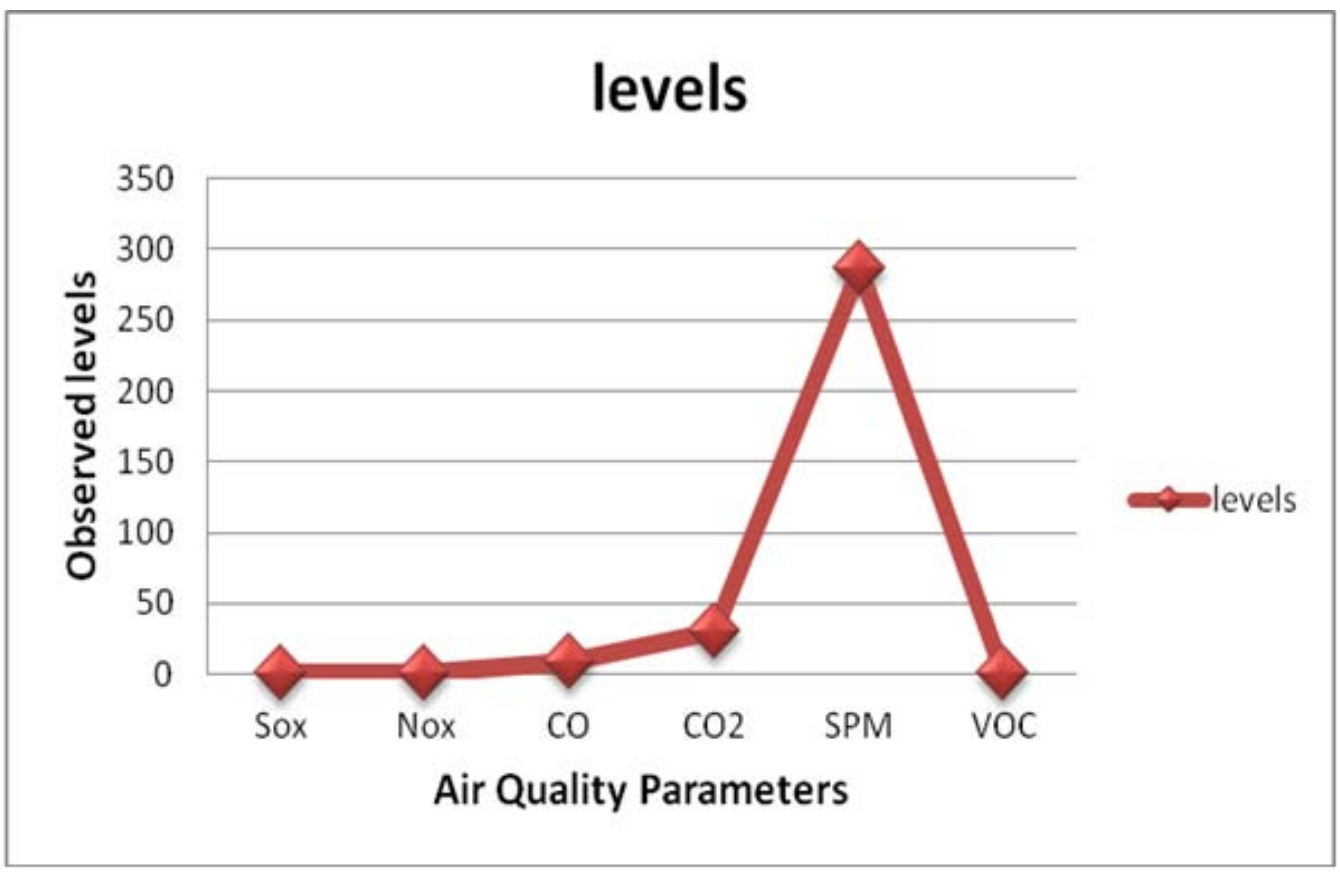

Figure 1: Graphical distribution of air quality parameters within the facility

\section{Discussion}

As seen in this study, the mean levels of noise and particulate matter concentrations exceeded permissible exposure limits. Thus noise and gaseous hydrocarbon emissions potentially constitute sources of occupational hazards to workers in this study, which agrees with similar findings of other authors [3]. In the oil and gas industry, temporal threshold shift could result from prolonged unprotected exposure to high noise levels[3]. This study showed that noise levels at the generator house and pump house exceeded normal permissible limits. This is in agreement with other studies that have shown that the sources of noise during the production phase in the oil industry include generator and turbine, compressor and pumps, producing wells, flow dynamics, and occasionally flaring[3]. While the primary impact of noise is on the workers who work in the facility daily for two weeks before embarking on two weeks' time-off, these condary impacts from noise could be localized disturbance to wildlife, recreationists, and residents. The risk of exposure to noise sources within the facility can be reduced to As Low as Reasonably Practicable (ALARP) by using the Hierarchy of Controls, [3].

These controls include the elimination of noisy equipment, substitute noisy equipment with other equipment that makes less noise, isolates equipment with noise absorbent materials, applies engineering controls to equipment that cannot be eliminated or substituted to reduce noise, apply procedural controls to reduce duration or magnitude of exposure, and 
provision of personal hearing protection. Furthermore, it is necessary that a comprehensive hearing conservation program (HCP)is put in place for all personnel exposed to noisy environments exceeding $85 \mathrm{dBb}$ (a).This program will include noise survey of suspected workstations, develop and deploy noise maps at facility entrances, identify exposed personnel, mandatory training on noise-induced hearing loss, mandatory annual audiometry, mandatory use of hearing protector, and compliance enforcement [13].

The presence of atmospheric pollutants poses an occupational health risk to the workers and environmental health risks to residents that reside near the generating facility. Common atmospheric pollutants encountered in different oil and gas sites include sulfur oxides $\left(\mathrm{SO}_{\mathrm{x}}\right)$, oxides of nitrogen $\left(\mathrm{NO}_{\mathrm{x}}\right)$, hydrogen sulfide $\left(\mathrm{H}_{2} \mathrm{~S}\right)$, carbon monoxide $(\mathrm{CO})$, sulfur dioxide $\left(\mathrm{SO}_{2}\right)$, hydrogen cyanide $(\mathrm{HCN})$, Ammonia $\left(\mathrm{NH}_{3}\right)$, particulate matter, heat radiation and noise [14].Three months' average air quality analysis revealed Suspended Particulate Matter (SPM) concentration of $287 \mu \mathrm{g} / \mathrm{m}^{3}$, which is above the Federal Ministry of Environment (FMENV) limit of $250 \mu \mathrm{g} / \mathrm{m}^{3}$. Depending on the chemical composition and size of the SPM, prolonged exposure renders workers and inhabitants of host communities vulnerable to chronic respiratory disease; impairment of visibility, sensory irritation, worsens hay fever, and allergies; stunts the growth of vegetation; and leads to decreased visibility[14]. SPM is composed of small particles that are suspended in the air and settles to the ground slowly[15].

The most common sources of particulate matter from oil and gas operations are dust from the separation of crude oil and associated water, and engines used to power machinery at oil and gas facilities. Particulate matter release into the atmosphere can also occur during venting and flaring operations [16].The analysis further revealed Volatile Organic Compounds (VOC) concentration of 30ppm, which is well above the FMENV limit of 20ppm. Volatile Organic Compounds (VOCs) are carbon-containing substances that readily evaporate into the atmosphere. Crude oil is a densely saturated carbon-containing substance, with Benzene and Toluene being the most common VOC in the oil and gas industry. They have the capacity to adversely affect lung function etc[14].

Also, Oxides of Sulphur $\left(\mathrm{SO}_{\mathrm{x}}\right)$ concentrations were $0.14 \mathrm{ppm}$ which lies above the FMENV limit of 0.01- $0.1 \mathrm{ppm}$. Exposure to $\mathrm{SO}_{2}$ at concentrations above 5.00 ppm could stimulate bronchio-constriction (as seen in asthma), aggravation of respiratory disease, impairment of pulmonary functions, irritation of eyes and pulmonary tract and reduced growth in plants. Sulfur dioxide reacts with other chemicals to form particulate pollution, which can damage the lungs and cause respiratory diseases; heart conditions, and premature death [16-18]. Oxides of Nitrogen $\left(\mathrm{NO}_{x}\right)$ concentrations were $0.25 \mathrm{ppm}$, which is above the DPR limit of $0.07 \mathrm{ppm}$ and FMENV limit of $0.04-0.06 \mathrm{ppm}$. The health impacts from $\mathrm{NO}_{x}$ include respiratory problems, heart conditions, and lung damage[16]. Carbon Monoxide (CO), concentration was 9ppm which is below the DPR limit of 8ppm. Prolonged and excessive exposure to an ambient accumulation of $\mathrm{CO}$ could bring about the formation of carboxy-hemoglobin and prevent oxygenation of blood, leading to suffocation and consequent death. It inhibits the blood's ability to carry oxygen and can cause dizziness, unconsciousness, and even death[14].

Several environmental challenges associated with petroleum exploration and production activities exist and are varied and multifaceted. Some of these problems include generation and disposal of aqueous effluent of oily waste, combustion of products of gas flaring at gathering stations and high environmental noise levels. One of the environmental problems associated with crude oil exploration and exploitation is linked to gas flaring[14].The Department of Petroleum Resources (DPR) in 2002 produced a revised version of its Environmental Guidelines and Standards for the Petroleum Industries in Nigeria (EGASPIN). This guideline is in addition to other existing regulations on industrial standards promulgated by the Federal Environmental Protection Agency, 1991 (now Federal Ministry of Environment) to improve environmental management performance in Nigeria. This notwithstanding, several oil installations still violate the regulatory limits[14]. Environmental contaminants from gas flaring include a number of oxides of Nitrogen, Carbon and Sulphur, particulate matteretc[14,19]. The flares also contribute to acid rain, whichcauses the corrosion of aluminium roofs, soil acidification etc.Acidic soils have been described as having lost its and this could be harmful to crops. [20-21].

\section{Conclusion}

From the findings of this study, it can thus be concluded that the activities of the flow station contribute to noise and air pollution which could have potentially deleterious effects on workers' health and the environment. It is thus recommended that apart from applying the usual methods of reducing noise effects, innovative ways to reduce the noise generated be utilized to reduce noise pollution around oil and gas facilities. Adequate technologies to stop the flaring practices should be developed by utilizing the Associated Gas for electricity generation using gas turbines and re-injecting the Associated Gas into the oil field to enhance crude oil recovery. Gas is being increasingly seen as a viable source of energy to speed up development needs in Africa. In Nigeria, though gas is wasted through flaring activities, creating harmful air pollutants and biomass, it is still the mainstay of cooking 
and other heating. Thus, attention should be paid to the reduction of gas flaring and channeling such gas for small-scale utilization such that it benefits the local communities.

Author Contributions: The author developed the study design and survey instrument, trained the research staff, and was involved in data analysis and manuscript preparation. He was also involved in data collection, data analysis and interpretation of the results.

Conflicts of Interest: The author declares no conflict of interest.

\section{References Références Referencias}

1. Nwaichi EO, Uzazobona MA. Estimation of the $\mathrm{CO}_{2}$ level due to Gas Flaring in the Niger Delta. Research Journal of Environmental Sciences, 2011, 5(6):565572.

2. Ajiboye $\mathrm{O}$, Jawando O,Adisa B. Poverty, oil exploration and Niger Delta crisis: The response of the youth.African Journal of Political Science and International Relations 2009, 3(5):224-232.

3. Wokocha G, Sopruchi C. Industrial Noise Level and its Impact on Oil Company Workers in Rivers State, Nigeria. Middle Eastern Finance and Economics, 2010, 8, 113.

4. Health and Safety Executive. Statutory instruments, 2005, 1643.

5. World Health Organization. WHO Regional Publications, European Series, No. 91: Air Quality Guidelines for Europe (2nd edition). Copenhagen 2000: 3, 277.

6. Markussen RW. Occupational and Public Health Issues in the Oil and Gas Industry: Emerging Trends and Needs for Emphasis (online). 2003; Available at: http://www.touchbriefings.com/pdf/25/westmark. pdf

7. Gardner R. Overview and characteristics of some occupational exposures and health risks on offshore oil and gas installations. Annals of Occupational Hygiene 2003; 47:201-210.

8. Cottle M, Guidotti TM. Process chemicals in the oil and gas industry: potential occupational hazards. Toxicology Industry Health. 1990, 69(1): 41-56.

9. Jewett RA. Health Hazards in the Oil Industry. Paper read before the Industrial Hygiene Section of the American Public Health Association at the 63rd Annual Meeting in Pasadena, Calif., Sept. 4, 1934.

10. Niven K, McLeod R. Offshore industry: management of health hazards in the upstream petroleum industry, Occupational Medicine, 2009, 99: 304-309.

11. Imevbore AA, Adeyemi SA. Environmental monitoring in relation to pollution and control of oil pollution. In Proc. Seminar on the petroleum industry and the Nigerian environment. 1981, $6: 135-142$.
12. Adekanmbi AO, Falodun Ol. Physicochemical, microbiological and heavy metal studies on water samples and bacteria obtained from Dandaru River in Ibadan, South-western Nigeria. African Journal of Microbiology Research, 2015, 9(20):1357-1365. DOI: 10.5897/AJMR2015.7388.

13. National Institute of Deafness and Other Communication Disorders. Tinnitus. NIDCD Fact Sheet, Hearing and Balance. U.S. Department of Health and Human Services. National Institutes of Health. 2014.

14. Orimoogunje OI, Ayanlade I, Akinkuolie TA,Odiong AU. Perception on Effect of Gas Flaring on the Environment. Research Journal of Environmental and Earth Sciences, 2010, 2(4): 188-193.

15. Axelong L. The State of the Major Air Pollutants, Source and Control. London Association, New York. 2000, 3:27 - 29 .

16. Iyayi F. An integrated approach to development in the Niger Delta. A paper prepared for Centre for Democracy and Development (CDD). 2004

17. Knight, L D." Death by Sewer Gas: Case Report of a Double Fatality and Review of the Literature," The America Journal of Forensic Medicine and Pathology, 2005, 26(26): 181-185.

18. Legator B.Health Effects from Chronic Low-Level Exposure to Hydrogen Sulphide. Archives of Environmental Health, 2001, 56: (2):123-131.

19. Kindzierski, WD. Importance of human environmental exposure to hazardous air pollutants from gas flares. Environ. Rev.2000, 8:41-62.

20. Amakiri JO, Onofeghara, FA. Effect of crude oil pollution on the growth of Zea mays, Abelmoschusesculentus and Capsicum frutescens. Oil \& Petrochemical Pollution,1983,1 (3):199-205.

21. Okezie DW, OkekeAO. Flaring of Associated Gas in Oil Industry: Impact on growth, Productivity, and Yield of Selected Farms Crops, Izombe Flow station Experience.Presentedat the NNPC Workshop, Port Harcourt.1987. 